\title{
Há Coisas Que Só Os Artistas Podem Fazer? Arquivar através de uma esteira de correr $^{1}$
}

\author{
Carolina Felice Bonfim \\ Universidade Livre de Bruxelas, Bruxelas, Bélgica \\ E-mail: carolina.felice.bonfim@ulb.ac.be
}

\section{Resumo}

Abstract

Este artigo busca compartilhar os métodos e as estratégias do projeto de pesquisa baseado na prática artística Ninety movements on a Technogym G6508D. Nessa pesquisa me concentro no ato de correr a fim de levá-lo ao extremo: fragmentá-lo, arquivá-lo, incorporá-lo e destacar o que há de único e pessoal em cada gesto e em cada forma de movimento. Ninety movements on a Technogym G6508D é a continuação de uma linha de trabalho que venho desenvolvendo ao longo dos últimos anos que, desde uma perspectiva pautada nas artes visuais e na performance, tem como tema central o corpo como arquivo.
This article seeks to share the methods and strategies of the practice-based research project Ninety movements on TECHNOGYM $G 6508 D$. The research dissects the act of running in all its dimensions by fragmenting, archiving, incorporating, and highlighting what is unique and personal in each gesture and each way of moving. Ninety movements on a Technogym G6508D is a continuation of Carolina Bonfim's recent artistic practice, which explores the relationship between the body and the archive through a visual-arts approach. 
A presente contribuição propõe uma análise autorreflexiva do projeto de pesquisa-criação Ninety movements on a Technogym G6508D, realizado durante o meu doutorado guiado pela prática artística². Ninety movements é um estudo sobre o ato de correr - no caso, em uma esteira da marca Technogym, modelo G6508D. Esse projeto é a continuação de uma linha de trabalho que venho desenvolvendo ao longo dos últimos anos que tem como tema central o corpo como arquivo vivo ${ }^{3}$. Dos diferentes enfoques que existem em relação ao corpo como arquivo, me interessa entender o modo como o nosso corpo pode se apropriar, incorporar e transmitir os gestos e a linguagem corporal do Outro. O que significa arquivar um corpo? Como essa operação se distingue do arquivamento tradicional de documentos e/ou de objetos? Como abordar os arquivos do corpo a partir de um conjunto de procedimentos e métodos que não aspiram necessariamente a autenticidade ou a fidelidade? Como o Outro pode ser incorporado, arquivado e transmitido? Como as linguagens artísticas podem nos ajudar a estudar os arquivos intan-

1 Este artigo foi publicado originalmente na revista FORUM+ (edição de outono de 2020): https://www.forum-online.be.

2 Doutorado realizado no Programa Artes e Ciências da Arte da Université Libre de Bruxelles e École Nationale Supérieure des Arts Visuels de La Cambre. Durante a pesquisa de doutorado, foram desenvolvidos três projetos artísticos: Ninety movements on TECHNOGYM G6508D, Not himself, not herself, not itself e Laboratorio sobre maneiras de buscar, destruir, inventar, ser e performar arquivo.

3 A correlação entre arquivo e corpo tem sido cada vez mais reivindicada por artistas e pensadores que consideram o corpo humano como um repositório de conhecimento, como um lugar de herança e como um veículo capaz de interligar passado, presente e futuro. O corpo como arquivo ou corpo-arquivo é um tópico que aparece na intersecção entre as artes visuais, a performance, o teatro, a dança, a música e as ciências humanas. Este texto não pretende apresentar um estado da arte sobre o tema, mas gostaria de mencionar alguns textos que nos oferecem diferentes perspectivas sobre o mesmo: The Body and the Archive (1986) de Allan Sekula, Dança da Guerra: Arquivo-Arma (1983) de Júlio Tavares; The Archive and the Repertoire: Performing Cultural Memory in the Americas (2003) de Diana Taylor; The Body as Archive: Will to Re-Enact and the Afterlives of Dances (2010) de André Lepecki. gíveis? Que abordagens são necessárias quando se lida com materiais que parecem ser 'inarquiváveis'? Estas são algumas das questões que tento responder através da minha prática artística. Foi, inclusive, o interesse pela noção de corpo como arquivo que me levou a realizar um doutorado, entendendo que o contexto acadêmico poderia me proporcionar uma compreensão mais ampla e poética sobre esse fenômeno. A seguir, descreverei o processo criativo de Ninety movements on TECHNOGYM G6508D, enfatizando as metodologias utilizadas; posteriormente, discutirei brevemente o trabalho artístico criado nesse processo e, por último, compartilharei alguns comentários e experiências resultantes do mesmo.

\section{Etapa 0: Antes de começar}

O processo criativo de Ninety movements on TECHNOGYM G6508D começou sem nenhuma metodologia pré-determinada. Entendo que na minha prática as escolhas metodológicas não antecedem o processo criativo e somente são compreendidas como tal quando o trabalho está finalizado. Cabe dizer que o projeto enviado para a seleção do doutorado não especificava os métodos e ações da pesquisa artística, tampouco foram indicados os resultados esperados, visto que o meu trabalho é guiado pela espontaneidade e a intuição. Em resumo, o objetivo principal do meu projeto de pesquisa se centrava em realizar uma série de propostas artísticas sobre o corpo como arquivo, sem especificar de antemão quais seriam as abordagens metodológicas de cada uma delas, visto que era necessário preservar um certo tipo de serendipidade, mesmo se tratando de um doutorado em artes.

\section{Etapa 1: Explorando o terreno}

Para realizar o doutorado, me mudei para Bruxelas, na Bélgica, lugar onde está situada a universidade. A primeira estratégia para iniciar o processo de criação nesse novo lugar foi caminhar pela cidade. Após alguns meses, muitos elementos foram observados e percebidos nessas caminhadas: paisagens, arquiteturas, pessoas, sons, idiomas, natureza, ani- 
mais, etc. E dentre eles, havia algo que chamava a minha atenção em especial: as pessoas que se exercitavam freneticamente atrás de uma vitrine de uma academia de ginástica localizada na rua onde eu morava. Todos os dias, quando saía para realizar a minha caminhada exploratória, fosse pela manhã, à tarde ou à noite, essas pessoas estavam lá se movimentando. Era como um grande palco que agrupava uma variedade de corpos que dificilmente eu encontraria reunida em outro lugar. Sem mencionar o fato de que esses corpos estavam lá em movimento constante durante todo o horário de funcionamento da academia, isto é, vinte e quatro horas por dia, sete dias por semana. Intrigada com essa cena, me matriculei na academia no dia 13 de maio de 2016. Embora eu não estivesse acostumada a frequentar esse tipo de lugar para me exercitar, não hesitei em experimentar o desconhecido. A partir desse momento, deixei de fazer as caminhadas pela cidade para me concentrar na exploração desse novo espaço.

Logo no primeiro dia, escolhi um aparelho de musculação que me proporcionava uma vista panorâmica da academia. De todas as coisas que vi, o que mais me intrigou foram os corpos correndo na esteira. Era como assistir uma coreografia da mesma ação realizada de maneiras diferentes, onde cada corpo mostrava seu vocabulário gestual próprio. Fiquei fascinada com esses corpos fazendo movimentos mecânicos e repetitivos que, em cada detalhe, revelavam algo particular. Assim, decidi em me concentrar no ato de correr em todas as suas dimensões: fragmentá-lo, arquivá-lo, incorporá-lo, destacar o que há de único e pessoal em cada gesto e em cada forma de movimento. Em síntese, a fim de observar detalhadamente esses corpos, estive correndo, juntamente com eles, durante noventa dias.

\section{Etapa 2: Apropriação}

Todos os dias, eu repetia a mesma ação: eu chegava à academia e me dirigia à mesma esteira de correr. Nesse mesmo espaço havia, em frente, uma outra fileira de doze esteiras e um grande espelho. Depois de ligar a máquina, eu escolhia aleato- riamente um corpo que estivesse correndo. Primeiro, eu arquivava meu objeto de estudo usando apareIhos de gravação de espionagem - como câmeras em forma de óculos, caneta e chaveiro - a fim de registrar o corpo observado sem chamar a atenção das pessoas. No início, para não perder nenhum detalhe, desejava registrar tudo, mas finalmente entendi que apenas dois minutos de gravação eram suficientes. Depois de realizar esse registro audiovisual, tentava repetir os movimentos do corpo correndo, observando-o in situ. A fim de identificar os mecanismos gestuais e rítmicos e para manter uma memória precisa do movimento a ser reproduzido, dividia o corpo observado em pontos de referência rosto, boca, ombros, joelhos e pernas - para facilitar a apropriação dos movimentos. Além dessas partes específicas, examinava também as articulações dos membros, a geometria das proporções, as ações mecânicas dos músculos, as condições de equilíbrio, os movimentos locomotores e assim por diante. A decifração desses corpos no meu próprio corpo é a forma como eu pude compreender na prática a apropriação do Outro. Durante esse trabalho de campo na academia, fiquei fascinada ao sentir meu corpo realizar uma ação trivial - correr - de maneiras que nunca havia imaginado antes. Todos os dias, quando chegava em casa, depois do 'treinamento', organizava as gravações e fotos, desenhava e anotava minha experiência em um caderno - que poderia ser considerado como um diário de bordo - documentando minuciosamente a minha experiência corporal.

Figura 1. Câmera espiã: caneta, 2017.

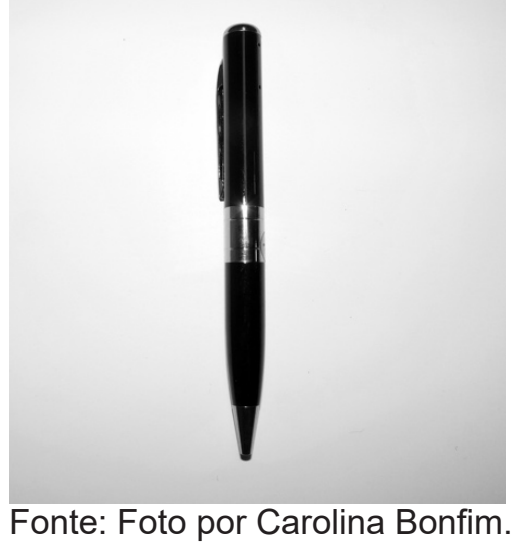

Fonte: Foto por Carolina Bonfim. 
Figura 2. Câmera espiã: chaveiro, 2017.

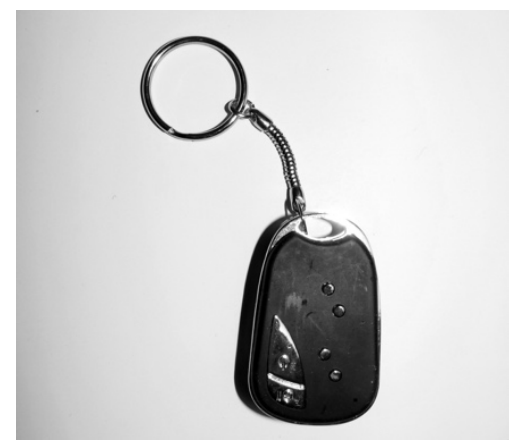

Fonte: Foto por Carolina Bonfim.

Figura 3. Câmera espiã: óculos, 2017.

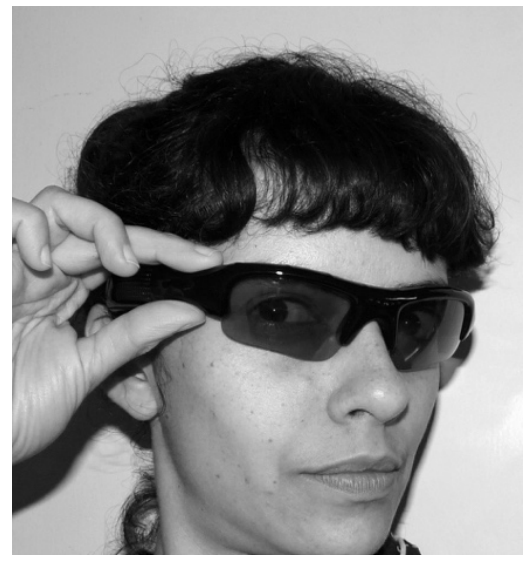

Fonte: Foto por Carolina Bonfim.

\section{Etapa 3: Incorporação}

O passo seguinte desse processo foi corporificar, encarnar ou simplesmente incorporar os outros corpos no meu. O que significa incorporar o Outro? De um ponto de vista prático, entendo a incorporação como um processo de alteração do próprio corpo através de sua constante fragmentação e recomposição. Nesse estudo, a dinâmica da incorporação requer uma rotina para reexaminar continuamente tudo o que foi apre(e)ndido durante a etapa anterior. Como a cada dia um novo corpo era incluído no meu arquivo, a repetição diária de todos os movimentos era fundamental. Para isso, assistia o vídeo do corpo correspondente e repetia os movimentos diversas vezes. Após alguns dias realizando a mesma ação, notava que os movimentos vinham naturalmente até chegar o momento em que assistir ao registro audiovisual não era mais necessário. A repetição e a apropriação são processos regulares, uma ação a ser praticada repetidamente, dia após dia, a fim de assimilar e fazer com que o Outro se funda no corpo.

Figura 4. Carolina Bonfim, Catálogo de movimentos, 2017, 180 impressões em papel formato A4, fichário, madeira, metal, $100 \times 68 \times 45 \mathrm{~cm}$, MARCO, Museu de Arte Contemporânea de Vigo.

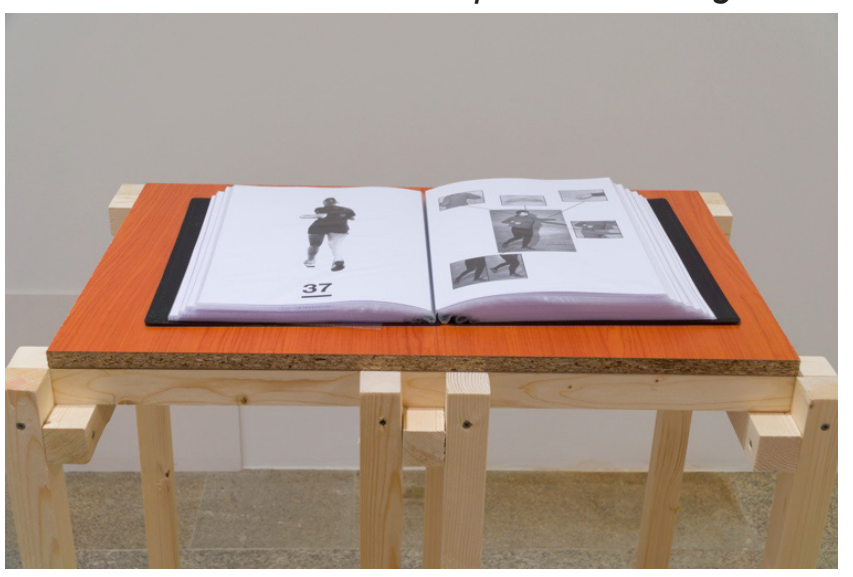

Fonte: Foto por Enrique Touriño.

\section{Etapa 4: Transmissão}

Depois de passar noventa dias na academia, analisei todo o material coletado a fim de refletir sobre como transformar essa experiência em um trabaIho artístico para ser apresentado em uma exposição. Eu me perguntava o que estava procurando e como queria transmitir o que havia experimentado até então. Como estratégica para compreender de que modo eu poderia elaborar o trabalho artístico, comecei a procurar por artistas que já haviam abordado os temas relacionados ao meu projeto. Seria como realizar um 'estado da arte' como uma forma de me situar e estabelecer diálogo sobre um assunto já desenvolvido por outras pessoas para, então, propor o meu próprio ponto de vista. Minha pesquisa mostrou que a academia de ginástica ou até mesmo o ato de correr foram tratados, através de diferentes perspectivas, por artistas como: Guillaume Bijl (Gym, 1983 e Fitness Center, 1985), Matthew Barney (Drawing Restraint, 1988), Collier Schorr (The Brothers A.M \& M., 2003), Lee Walton (Baseball's Cartographer, 2004), Mads Lynnerup (Plastic Gymnastic, 2012), Alexandra Bachzetsis (The Stages of Staging, 2013) e Aldo Giannotti (The Museum as a Gym, 2016). Es- 
ses referentes me ajudaram a compreender que meu foco principal não era a academia de ginástica como lugar - mesmo este sendo um objeto de estudo tentador - mas sim os corpos que foram arquivados. Portanto, escolhi uma forma intermediária para transmitir a minha experiência, isto é, que não omitisse a academia nem que se limitasse a ela. Como a minha pesquisa trata sobre as questões relacionadas ao corpo como arquivo vivo, me parecia pertinente evidenciar todas as principais etapas do processo, ou seja, a apropriação, a incorporação e a transmissão.

Assim, o primeiro trabalho que criei foi um catálogo de movimentos a partir dos registros obtidos durante a etapa de apropriação dos corpos. Para concebê-lo, visitei a Faculdade de Medicina da Universidade Livre de Bruxelas para consultar a bibliografia das seções de Fisioterapia e Educação Física enfocada na ilustração e na interpretação dos movimentos do corpo. Para as fichas do catálogo, escolhi manter a imagem real do corpo arquivado e, por outro lado, a 'tradução' do movimento através do meu próprio corpo.

Figura 5. Carolina Bonfim, Detalhe do Catálogo de movimentos, 2017, impressão em papel formato A4,, MARCO, Museo de Arte Contemporánea de Vigo.
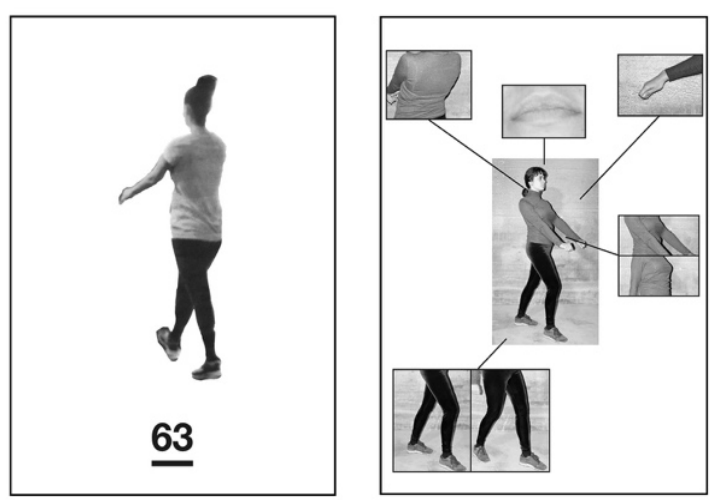

Fonte: Foto por Enrique Touriño.

A segunda obra consiste em um conjunto de painéis que, através dos pontos de referência-rosto, boca, ombros, joelhos e pernas - mostram o resultado da experiência da etapa de apropriação, isto é, as linhas, as densidades e a expressividade dessas partes do corpo.
Figura 6. Carolina Bonfim, Painel 4, 2017, impressão, madeira, metacrilato, $171 \times 98 \times 5 \mathrm{~cm}, \mathrm{MARCO}$, Museo de Arte Contemporânea de Vigo.

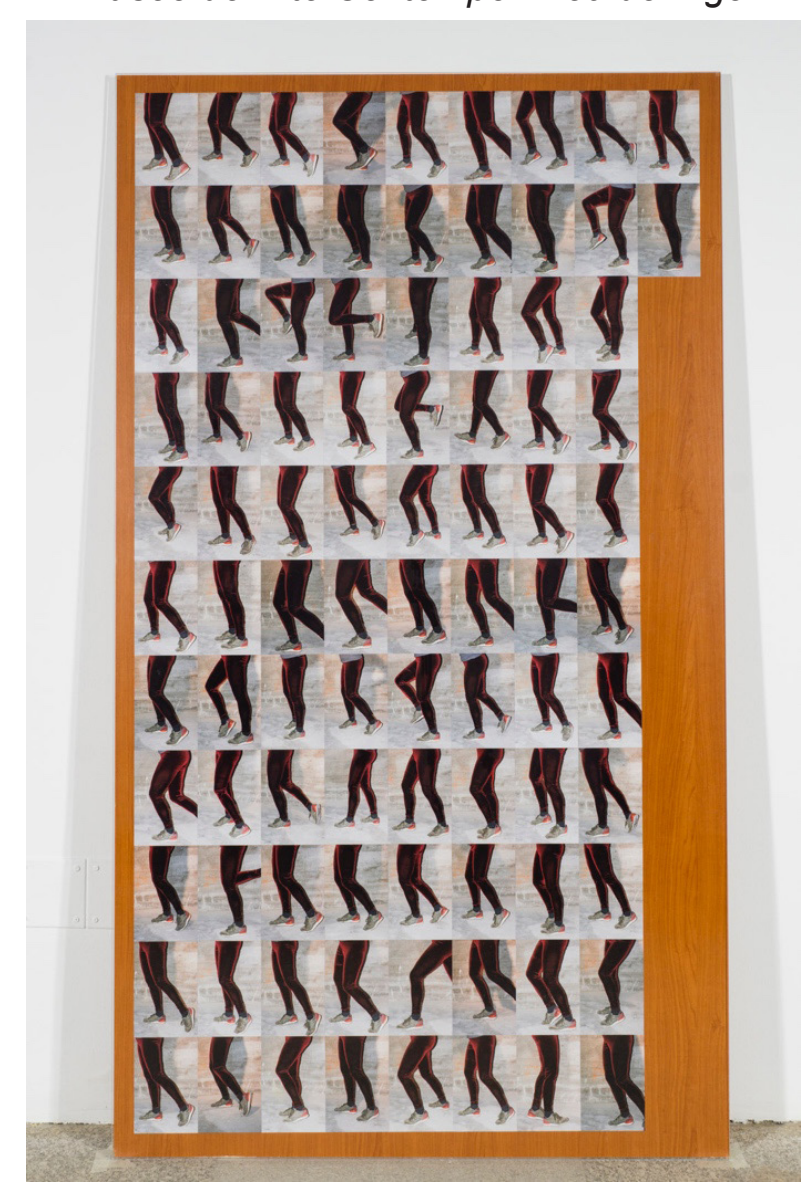

Fonte: Foto por Enrique Touriño.

A terceira obra é um vídeo inspirado nos exercícios de repetição dos movimentos realizados durante as etapas de apropriação e incorporação. O vídeo evidencia a transformação do meu corpo em movimento. 
Figura 7. Carolina Bonfim, 90 movements on TECHNOGYM G6508D, frame do vídeo, 2017.

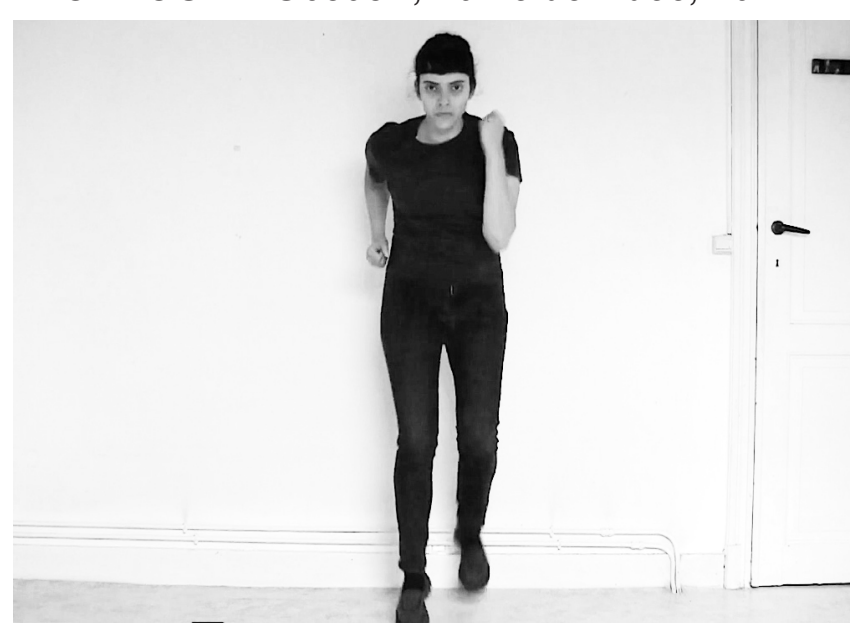

Fonte: Foto por Carolina Bonfim.

Essas três obras foram mostradas em uma exposição individual intitulada Ninety movements on TECHNOGYM G6508D ${ }^{4}$. Após a exposição, foi necessário tomar distância do processo para poder analisar a experiência vivida e compreender as abordagens metodológicas e artísticas envolvidas. Todo processo artístico tem a sua própria metodologia, por mais incomum e singular que possa parecer ou, até mesmo, por mais próxima dos procedimentos da pesquisa acadêmica que possa estar. Isso me fez lembrar da exposição Cosas que solo un artista puede hacer, curada por David Arlandis e Javier Marroquí para o Museu de Arte Contemporânea de Vigo, em 2010. Essa exposição abordou as metodologias, os procedimentos e as abordagens práticas que vinte artistas utilizaram para realizarem seus projetos. Andando pelas diferentes salas do museu, o visitante descobria - através de registros, notas e arquivos do processo - como, por exemplo, o artista Piero Golia tornou-se o primeiro italiano a pedir asilo na Albânia ou como Tere Recarens 'varreu' as nuvens de Berlim para deixar o sol brilhar na cidade, ou mesmo como Xu Zhen invadiu os países que fazem fronteira com a China. Diferente do que estamos acostumados a ver nos museus, Cosas que solo un artista puede ha-

4 Para mais informações sobre a exposição: www.marcovigo.com/es/node/2410, acessado no dia 20 de junho de 2020 . cer convidava os visitantes a mergulharem nos processos de criação e a imaginarem como os artistas chegaram até ao resultado final dos seus trabalhos.

Não há duvidas o quão interessante pode ser para o público ao descobrir como se desenvolve o processo criativo dos artistas, mas o que acontece quando o artista se dá conta dos detalhes do seu próprio processo? Nessa reflexão, gostaria de comentar brevemente sobre como a evidenciação das metodologias utilizadas durante Ninety movements on TECHNOGYM G6508D impactou na minha própria prática artística. É possível que, se esse projeto não tivesse sido criado no contexto de um doutorado, eu jamais teria refletido sobre como se deram as suas escolhas metodológicas. Ao pensar sobre esse processo criativo, tive a impressão de ter revelado ou sistematizado algo que havia sido guiado, desde o princípio, pela intuição, de modo que o ato de escrever sobre o processo, nomear cada passo e formular as sensações sentidas, me fizeram tomar consciência de algo que antes não me interessava racionalizar. Escrever sobre o meu próprio processo de criação e em diálogo com outras práticas e discursos (de artistas, teóricos, etc.), nunca havia acontecido de forma tão minuciosa até colocar o meu trabalho em diálogo com o contexto acadêmico. Se o ato de escrever é, para alguns artistas, uma forma de entender a própria prática, para outros - e eu me incluo nesse grupo - revela algo que pode afetar completamente a maneira como se trabalha.

Ao desvelar os procedimentos de minha própria prática, é como se o desejo de arquivar o Outro em meu próprio corpo tivesse deixado de me interessar. Como foi mencionado anteriormente, Ninety movements on TECHNOGYM G6508D segue uma série de trabalhos que venho realizando desde 2010 pautada no estudo de ações consideradas triviais, como andar, nadar, correr, beber, olhar, dançar, sentar, entre outras. De certa maneira, esses trabalhos seguiam, sem que eu fosse consciente, uma mesma metodologia de trabalho. No livro Manual de um Coreógrafo, Jonathan Burrows pergunta: "Como podemos recuperar esse estado de ignorância apaixo- 
nada, em que podemos escolher o que queremos saber, ao invés de saber tudo?" $\left(2010\right.$, p. 22) ${ }^{5}$. A pergunta de Burrows sobre a reflexão do processo criativo descreve com precisão meus sentimentos ao evidenciar cada parte do meu próprio processo. É possível reencontrar o estado de ignorância e esquecer tudo aquilo que foi descoberto? Reconheço que ser consciente das minhas próprias metodologias não foi, no início, muito agradável, mas, ao mesmo tempo, isso me levou a procurar novas formas de trabalhar ou mesmo repensar em como eu gostaria de continuar fazendo arte. Como Mika Hannula, Juha Suoranta e Tere Vadén sugerem, a pesquisa artística é "sobre os processos autorreflexivos e autocríticos de uma pessoa que participa na produção de sentido dentro da arte, e de tal forma que comunica de onde vem, onde está neste preciso momento, e para onde quer ir" $(2005, \text { p. } 10)^{6}$. Embora eu tenha sentido, depois de Ninety movements on TECHNOGYM G6508D, que meu corpo não precisava mais experimentar os arquivos dos outros, o corpo como arquivo ainda me interessa como objeto de estudo e me fez perceber que eu tinha que tomar um novo caminho de experimentação.

Para concluir, vejo que ao descrever os procedimentos utilizados ao longo desse projeto, alguns destes poderiam dialogar com certas metodologias da pesquisa científica. Artistas e acadêmicos têm de fato muitas coisas em comum, tais como a imaginação, a especulação, a introspecção, o acaso e, especialmente, a intuição. Além disso, a pesquisa artística ao ser entendida como uma atividade de produção, exploração e reflexão - seja ela pontuada ou não por dúvidas, fracassos, tentativas ou descobertas - não é diferente de outros processos de pesquisa. Talvez as práticas artísticas possam proporcionar ao panorama acadêmico um novo frescor através dessa forma

5 BURROWS, Jonathan. A Choreographer's Handbook. London/New York, Routledge, 2010, p. 22.

6 HANNULA, Mika; SUORANTA, Juha; VADÉN, Tere. Artistic Research: Theories, Methods and Practices. Academy of Fine Arts, Helsinki, Finland and University of Gothenburg, Sweden, 2005, p. 10. singular de lidar com o processo - muitas vezes sem hipótese, sem métodos pré-estabelecidos e que escapa de um modelo padronizado de fazer pesquisa.

\section{Referências}

BURROWS, Jonathan. A Choreographer's Handbook. London/New York: Routledge, 2010.

HANNULA, Mika; SUORANTA, Juha; VADÉN, Tere. Artistic Research: Theories, Methods and Practices. Academy of Fine Arts, Helsinki: Finland and University of Gothenburg, Sweden, 2005.

Recebido: 12/04/2021

Aceito: $17 / 05 / 2021$

Aprovado para publicação: 29/05/2021

Este é um artigo de acesso aberto distribuído sob os termos de uma Licença Creative Commons Atribuição 4.0 Internacional. Disponível em: <http://creativecommons.org/licenses/by/4.0>.

This is an open-access article distributed under the terms of the Creative Commons Attribution License 4.0 International. Available at: <http://creativecommons.org/licenses/by/4.0>.

Ce texte en libre accès est placé sous licence Creative Commons Attribution 4.0 International. Disponible sur: <http://creativecommons.org/licenses/by/4.0>. 